\title{
EVOLUCIÓN DEL DAÑO MORAL POR TÉRMINO DEL CONTRATO DE TRABAJO EN EL DERECHO CHILENO
}

["Progression of Moral Damage for Termination of Contract of Employment in Chilean Law"]

\author{
Sergio Gamonal* \\ Universidad Adolfo Ibáñez, Santiago de Chile
}

\begin{abstract}
RESUMEN
Este artículo revisa la evolución del Derecho chileno en materia de indemnización del daño moral debido a término de contrato, por sobre las indemnizaciones legales tarifadas por antigüedad. Se analizan los casos en que se han adjuntado excepcionalmente indemnizaciones extras a las tarifadas en despidos abusivos. Luego se estudia el daño moral en el nuevo despido atentatorio de derechos fundamentales, y se verifica la existencia de una evolución desde un escenario doctrinario a uno legal, con indemnizaciones adicionales que dan cuenta del daño moral sufrido por el trabajador.

Palabras Clave

Daño moral - Indemnización tarifada - Despido abusivo.
\end{abstract}

\section{Abstract}

This article deals with the progression of indemnities for moral damage due to termination of contract of employment over legal compensations rated by seniority in the Chilean law. There is an analysis of the cases where additional compensations were exceptionally granted as well as the seniority-rated compensations in cases of wrongful dismissals. Then, there is an analysis of moral damage in the new dismissals that breach the fundamental rights and a verification of the existence of progress from a doctrinaire approach to a legal one, with additional compensations for the moral damage suffered by an employee.

\section{KEYWORDS \\ Moral damage - Compensation rated} by seniority - Wrongful dismissal.

Recibido el 6 de agosto y APROBADo el 1 de octubre de 2012.

* Profesor de Derecho del trabajo en la Universidad Adolfo Ibáñez, Santiago, Chile. Dirección postal: Avda, Diagonal Las Torres 2640, Peñalolen, Santiago, Chile. Correo electrónico: sergio.gamonal@uai.cl 


\section{EL DAÑo MORAL Y EL DERECHO DEL TRABAJO}

Para entender la relevancia del daño moral por término del contrato de trabajo, es necesario hacer previamente una breve referencia acerca del daño moral y del derecho del trabajo en general.

La doctrina he precisado que el daño moral en materia laboral puede darse en diversos supuestos, tanto en una etapa precontractual, de ejecución del contrato, al término del mismo y postcontractual, generándose, según el caso, responsabilidad contractual o extracontractual ${ }^{1}$.

En la etapa precontractual, puede producirse un daño moral en el proceso de selección del trabajador, violentando su derecho a la intimidad si se le solicitan datos personales más allá de lo razonable o necesario para determinar su experiencia y capacidad. Asimismo, puede transgredirse su derecho a la vida privada indagando en su situación familiar, sus actividades de recreación, las actividades que realiza con su familia en el período de vacaciones, sus convicciones políticas, religiosas o sindicales. Lo mismo ocurre con las listas negras, que afectan y dañan el derecho a la imagen del trabajador ${ }^{2}$.

En la etapa de ejecución del contrato nada impide que cuando se incumplen obligaciones, que no impliquen su término, pueda resarcirse el daño moral ${ }^{3}$.

Encontramos muchas situaciones durante el desarrollo del contrato que pueden producir un daño moral, como ocurre con el uso abusivo del jus variandi o cuando se vulnera el derecho a la intimidad del trabajador, por las medidas de revisión y control que establezca la empresa. Del mismo modo, puede afectarse la honra del trabajador cuando se le sanciona disciplinariamente en forma infundada, por ejemplo por falta de honradez, en virtud del poder de mando del empleador.

Existe acuerdo en que el empleador no puede intervenir en la vida familiar, religiosa o política del trabajador, y que las libertades públicas tienen cierta

\footnotetext{
${ }^{1}$ Gamonal, Sergio, El daño moral en el contrato de trabajo (2a edición, Santiago, LexisNexis, 2007), pp. 21 ss.

${ }^{2}$ Süsseskind, Arnaldo - Maranhäo, Délio - Vianna, Segadas - Texeira, Lima, Instituçiôes de Direito do trabalho (Sao Paulo, LTr, 1997), I, pp. 631 ss.

${ }^{3}$ Pizarro, Ramón Daniel, Daño moral (Buenos Aires, Hammurabi, 1996), pp. 606 y 607. En Chile, con el nuevo procedimiento de tutela y según lo dispuesto en el artículo $495 \mathrm{~N}^{\circ} 3 \mathrm{CT}$., perfectamente puede resarcirse el daño moral durante la ejecución del contrato. Un ejemplo está dado en la causa RIT T-38-2010, del Primer Juzgado de Letras del Trabajo de Santiago, que condena a una empresa a pagar 5 millones de pesos a una trabajadora discriminada por ser musulmana. El juicio fue tramitado estando el contrato de trabajo vigente.
} 
proyección dentro de la empresa, consagrándose la denominada ciudadanía en la empresa ${ }^{4}$.

Producido un daño moral durante el contrato, procede pedir la reparación del daño y es factible también solicitar el cese de las acciones que continúan provocando sus efectos en el tiempo 5 .

Además, durante la ejecución del contrato, puede producirse un accidente del trabajo o una enfermedad profesional, donde expresamente la ley chilena contempla la reparación del daño moral, al tenor de lo dispuesto en el artículo 69 letra b) de la ley No 16.744. Esta responsabilidad es de naturaleza contractual, en caso de que el accidente o enfermedad se deba a culpa o dolo de la entidad empleadora, claramente deducida del deber de seguridad que establece el artículo 184 CT.

En materia de término de contrato, encontramos en Chile desde fines de los años 90 sentencias que condenan al empleador a pagar, por medio de la responsabilidad extracontractual, el daño moral generado por el despido abusivo ${ }^{6}$.

${ }^{4}$ CaAmaño, Eduardo, El derecho a la no discriminación en el empleo (Santiago, LexisNexis, 2005); Gamonal, Sergio, Ciudadania en la empresa o los derechos fundamentales inespecificos (Montevideo, Fundación de Cultura Universitaria, 2004); GAmonal, Sergio, El procedimiento de tutela de derechos laborales (2a edición, Santiago, LexisNexis, 2008); MeLIs, Christian, Los derechos fundamentales de los trabajadores como limites a los poderes empresariales (Santiago, LegalPublishing, 2009); UGARTE, José Luis, El nuevo Derecho del trabajo (Santiago, Editorial Universitaria, 2004); y Ugarte, José Luis, Tutela de derechos fundamentales del trabajador (Santiago, LegalPublishing, 2009).

${ }^{5}$ VázQuez Vialard, Antonio, La responsabilidad en el Derecho del trabajo (Buenos Aires, Astrea, 1988), p. 766.

${ }^{6} \mathrm{El}$ primer caso fue "Florencio Céspedes Ortiz con Banco del Estado" (Rol interno del tribunal N ${ }^{\circ}$ 698-97), publicado en la Revista Chilena de Derecho, 25 (abril-junio de 1998) 2, y comentada en esa edición por Domínguez Águila, Ramón, Reparación del daño moral por despido injustificado, pp. 431-445. Antes del año 1990 encontramos algunas sentencias que condenan al daño moral laboral por responsabilidad contractual, en base a la invocación maliciosa de ciertas causales de término, al tenor del artículo 162 CT. de 1987. Luego, con la ley N 19.010, este artículo fue derogado. Cfr. GAMONAL, Sergio, El daño moral por término de contrato de trabajo (Santiago, Editrem, 2000) pp. 56 ss. y 74. Cabe hacer presente que autores como Fueyo y Tomasello habían considerado la posibilidad de indemnizar el daño moral por término de contrato de trabajo. El primero citaba un caso de jurisprudencia española sobre daño moral por un contrato de trabajo que se terminó aduciendo un supuesto delito y una jurisprudencia arbitral chilena, en la cual se niega lugar al daño moral pero se lo admite, a modo ejemplar, en otros supuestos para el contrato de trabajo. En este último caso, el referido fallo arbitral precisaba: "Evidentemente, si el empleador maltrata físicamente al empleado o atenta de algún modo a su honor, la infracción contractual dará origen a un daño moral indemnizable, porque el hecho constitutivo de la infracción es idóneo para producir 
Por último, cabe agregar que en la etapa postcontractual puede producirse un daño moral, por ejemplo, cuando el empleador injuria al trabajador durante el juicio por despido injustificado. En este caso la responsabilidad será extracontractual.

En este trabajo nos abocaremos al fundamento constitucional de la reparación del daño moral, para luego revisar algunas de las hipótesis (tradicionales y nuevas) y sentencias más relevantes en la materia, con miras a argumentar que la reparación del daño moral en Chile se ha fortalecido al pasar de un origen doctrinario y jurisprudencial a un fundamento expreso en el Código del Trabajo.

\section{FUndAMENTO CONSTITUCIONAL}

La indemnización del daño moral ha sido acogida en Chile como principio a nivel constitucional, dentro la denominada constitucionalización del Derecho civil7.

La Constitución chilena hace referencia al daño moral en su artículo 19 No $7^{\circ}$ letra i), al contemplar el derecho a ser indemnizado por el Estado por los perjuicios patrimoniales y morales causados por el error judicial. Asimismo, su artículo 38 inciso $2^{\circ}$ dispone: "Cualquier persona que sea lesionada en sus derechos por la Administración del Estado, de sus organismos o de las municipalidades, podrá reclamar ante los tribunales que determine la ley, sin

un daño de esa índole". Véase: Fueyo LANeri, Fernando, Instituciones de Derecho civil moderno (Santiago, Editorial Jurídica de Chile, 1990). El segundo, a fines de los 60 contemplaba en su obra sobre daño moral la reparación del daño moral en la terminación del contrato de trabajo; véase: TOMASELlo HART, Leslie, El daño moral en la responsabilidad contractual (Santiago, Editorial Jurídica de Chile, 1969), p. 281.

${ }^{7}$ GuZMán Brito, Alejandro, El Derecho privado constitucional de Chile (Valparaíso, Ediciones Universitarias de Valparaíso Universidad Católica de Valparaíso, 2001), pp. 27 y ss.; y Diez SCHWERTER, José Luis, El daño extracontractual. Jurisprudencia y doctrina (Santiago, Editorial Jurídica de Chile, s.l., 1997) p. 102. Sobre el fundamento constitucional de la indemnización del daño moral consúltense: Domínguez, Carmen, La indemnización por daño moral. Modernas tendencias en el derecho civil chileno y comparado, en Revista Chilena de Derecho, 25 (1998) 1, p. 38; Domínguez Águila, Ramón - Domínguez Benavente, Ramón, Daño moral en la responsabilidad contractual. Ausencia de norma excluyente de su reparación. Comentario de Jurisprudencia, en Revista de Derecho, 196 (Universidad de Concepción, julio/diciembre de 1994), p. 158; Domínguez Águila, Ramón - Domínguez Benavente, Ramón, Responsabilidad contractual. Daño moral. Cúmulo de responsabilidades. Prueba del daño moral, Comentario de Jurisprudencia, en Revista de Derecho, 193 (Universidad de Concepción enero-junio de 1993), p. 163; e Illanes Ríos, Claudio, El daño moral en la responsabilidad contractual, charla dictada el 8 de septiembre de 1994 en el Colegio de Abogados, publicada en diciembre de 1994 por el Colegio de Abogados, p. 7. 
perjuicio de la responsabilidad que pudiere afectar al funcionario que hubiere causado el daño". Se estima que dicho reclamo comprende el daño moral, toda vez que la Constitución no lo excluye expresamente su reparación.

Por otra parte, en el artículo $19 \mathrm{~N}^{\circ} 24^{\circ}$ inciso $3^{\circ}$, excluye en forma expresa la reparación del daño moral al disponer que el expropiado tenga derecho a la indemnización por el daño patrimonial efectivamente causado.

La Constitución en su artículo $19 \mathrm{~N}^{\circ} \mathrm{s} .1^{\circ}$ y $4^{\circ}$, refuerza el reconocimiento del daño moral al consagrar como garantías constitucionales el derecho a la vida y a la integridad física y psíquica de la persona $\left(\mathrm{N}^{\circ} 1^{\circ}\right)$, y el respeto y protección a la vida privada y a la honra de la persona y de su familia $\left(\mathrm{N}^{\circ} 4^{\circ}\right)$.

Para Diez Schwerter las normas anteriores implican que la reparación de los perjuicios extrapatrimoniales contemplados en la Constitución debe aceptarse en cualquier ámbito de la responsabilidad civil: precontractual, contractual y extracontractual ${ }^{8}$.

Domínguez Águila señala que nuestra Constitución consagra plenamente el principio de reparación integral del daño, tanto respecto del daño moral en los numerales $1^{\circ}$ y $4^{\circ}$ del artículo 19 , como en lo referente al daño patrimonial en el numeral $24^{\circ}$ del citado artículo?.

La Corte Suprema, en una clásica sentencia civil ${ }^{10}$, fundamenta su decisión favorable a la indemnización de los daños morales contractuales por lo dispuesto en los numerales $1^{\circ}$ y $4^{\circ}$ del artículo 19 C.Pol., en relación con lo señalado en el artículo $1^{\circ}$ de la Constitución, en cuanto declara que "el Estado está al servicio de la persona humana y que su finalidad es promover el bien comun, para lo cual debe contribuir a crear las condiciones sociales que permitan a todos y cada uno de los integrantes de la comunidad nacional su mayor realización espiritual y material posible, con pleno respeto a los derechos y garantías que esta Constitución establece"11.

Para la Corte esta concepción filosófica corresponde a una corriente de pensamiento universal, como se desprende de diversos acuerdos internacionales, como por ejemplo en la Declaración americana de los derechosy deberes del hombre, que en su artículo 5 establece: "Toda persona tiene derecho a la protección de la ley contra ataques abusivos a su honra, reputación y a su vida privada y familiar"; y el "Pacto de San José de Costa Rica" que en su artí-

${ }^{8}$ Diez Schwerter, José Luis, cit. (n. 7), pp. 104 a 106.

${ }^{9}$ Domínguez, Ramón, Reparación del daño moral por despido injustificado, en Revista Chilena de Derecho, 25 (1998) 2, p. 441.

${ }^{10}$ Fallos del Mes, 431 (1994), pp. 657 a 663. Se trata del caso "María Rafart Mouthon con Banco de Chile", casación en el fondo, 29 de octubre de 1994, Rol interno del tribunal No 18.647.

${ }^{11}$ Considerando $10^{\circ}$. 
culo 11 dispone que toda persona tiene derecho al respeto de su honra y al reconocimiento de su dignidad ${ }^{12}$.

En consecuencia, tanto para la doctrina nacional como para nuestra jurisprudencia, la reparación del daño moral contractual y extracontractual tiene plena justificación en el orden constitucional chileno, lo cual, como analizaremos en los próximos acápites, es de gran importancia para el derecho laboral.

\section{HipÓtesis TRADICIONAL DE DAÑO MORAL LABORAL POR TÉRMINO DE CONTRATO}

La relación de trabajo es típicamente una relación de poder y, por lo mismo, impone derechos y obligaciones que utilizados en forma abusiva pueden causar daños patrimoniales y extrapatrimoniales.

En materia de terminación del contrato de trabajo, la simple disolución del vínculo contractual es un derecho del empleador cuando se configura una de las causales establecidas por ley. En estos casos, aunque pueda existir un daño moral no procede su reparación, sin perjuicio del pago de la indemnización por años de servicio en el caso de los contratos de trabajo indefinidos. Esta indemnización procede en el caso del despido por necesidades de la empresa o por desahucio, y es tarifada por antigüedad.

Con este sistema, nuestro Código del Trabajo (al igual que en muchos países) crea un sistema especial de indemnizaciones por término de contrato. Por un lado, el trabajador no está obligado a probar perjuicios, lo cual le es muy conveniente. Por otro lado, el empleador sabe de antemano el costo del despido. En este contexto, en principio, no cabe demandar otras indemnizaciones $^{13}$. Sin embargo, existen situaciones excepcionales en las cuales puede plantearse la necesidad de reparar el daño moral cuando se configura un despido abusivo.

¿Qué deberemos entender por despido abusivo? Un despido injustificado o erróneo no es, en principio, abusivo. El despido abusivo alude a un despido excepcionalmente antijurídico ${ }^{14}$. Por ejemplo, hay casos en que el empleador

\footnotetext{
${ }^{12}$ Considerando $11^{\circ}$.

${ }^{13}$ Cabe precisar que el sistema chileno es muy flexible, dado, que en los casos del contrato a plazo y por obra o servicio, no se paga indemnización por años de servicio (arts. $159 \mathrm{~N}^{\text {os }} 4$ y 5). Por tanto, en Chile, el 85\% de los despidos son por este tipo de contratación precaria (plazo u obra o servicio), lo que deja a la indemnización por años de servicio como una institución marginal. La doctrina chilena califica esta amplia flexibilidad como flexiprecariedad. Véase: Gamonal, Sergio, Trabajo y Derecho (Santiago, AbeledoPerrot, 2010), pp. 197 ss.

${ }^{14}$ Ermida define en forma amplia el despido abusivo como aquel que se adopta sin
} 
construye falsamente una causal de gravedad con el objetivo de no pagar las indemnizaciones por término de contrato.

Respecto de la posibilidad de acumular una indemnización por daño moral a la tarifada establecida por ley, se distinguen diversas opiniones en doctrina ${ }^{15}$. Para algunos es improcedente la referida acumulación toda vez que terminado el contrato debe cancelarse la indemnización tarifada establecida por ley, la cual excluye del ámbito de la relación laboral el principio general de la reparación integral de los daños.

Se sostiene, además, que la tarifa legal abarca todos los eventuales perjuicios producidos por el despido injustificado, correspondiendo su pago se hayan o no producido daños para el trabajador. Complementa lo anterior, el hecho de que el legislador ha establecido una indemnización tarifada a fin de que el costo económico que su pago representa para el empresario no afecte la continuidad de la actividad productiva, y que éste pueda planificar previamente el desarrollo de su negocio ante la posibilidad de tener que cancelar las indemnizaciones por despido. En caso contrario, se produciría una grave inseguridad jurídica en las relaciones de trabajo.

Se agrega que no es posible aplicar las normas del derecho común al derecho laboral, cuando éste ha regulado en forma expresa una determinada institución, como ocurre con las indemnizaciones por término de contrato, y que si el legislador hubiere deseado establecer una indemnización mayor, lo habría hecho expresamente.

Por el contrario, para la mayor parte de la doctrina es plenamente pertinente la acumulación de una indemnización del daño moral por despido abusivo con las establecidas por el derecho laboral para el término del contrato de trabajo.

En esta línea se argumenta que la indemnización tarifada sólo cubre el daño patrimonial del despido, por lo cual resulta de toda lógica la necesidad de indemnizar el daño moral por ejercicio abusivo del despido con una indemnización complementaria.

Se añade que la aceptación de la indemnización del daño moral por térmi-

justa causa o motivo justificante (o con un motivo o causa desviado, disfuncional, o antifuncional), o con mala fe o deslealtad. Cfr. Ermida, Oscar, El concepto de despido abusivo, en Derecho Laboral, 27 (Montevideo, julio-septiembre de 1984), 135, pp. 509 y 521 . Otros autores han precisado que para que se configure un despido abusivo no es suficiente que haya inexistencia de causa o de justa causa en el despido, sino que es necesario que el empleador cometa un hecho ilícito o incumplimiento contractual distinto del deber de conservar el empleo del trabajador. Véase: MANGarelli, Cristina - Rosenbaum Rimolo, Jorge, El despido abusivo en el derecho uruguayo, en Derecho Laboral, 31 (Montevideo, julio-septiembre de 1988)151, p. 529.

${ }^{15}$ Martorell, Ernesto, Indemnización del daño moral por despido (2a edición, Buenos Aires, Hammurabi, 1994), pp. 145 ss. 
no de contrato, en casos de especial gravedad, podría fortalecer la seguridad jurídica en el entendido de que la jurisprudencia o la ley fijen pautas respecto de los casos y montos de su indemnización.

Se ha sostenido, por otra parte, que debe repararse el daño moral cuando se produce por actos diferentes del despido, los cuales importan incumplimientos contractuales o actos ilícitos. Se trata de actos del empleador que pueden ser previos, simultáneos o posteriores al despido.

Se ha postulado también que la existencia de un régimen específico de indemnización tarifada por término de contrato no autoriza para concluir, a contrario sensu, que en materia laboral no rige el principio de reparación integral del daño.

Por las razones anteriores, se ha tendido a aceptar la posibilidad de acumular, a la indemnización tarifada legal por término de contrato, otra de daños y perjuicios morales cuando éstos adquieren cierta relevancia y entidad ${ }^{16}$.

Este es el camino que ha seguido la jurisprudencia nacional. Como señalamos en acápites anteriores (véase la nota 6), un primer caso fue el sentenciado por la Corte de Apelaciones de Concepción, de 12 de diciembre de 1997, en la causa "Florencio Céspedes Ortiz con Banco del Estado"17, por un despido por falta de probidad en el cual se le imputa al trabajador el haber usufructuado dineros provenientes de créditos otorgados por él, y el haber concedido créditos sin suficiente garantía. Otra sentencia relevante es "Retamal García con Comercial Automotora del Maule S.A. (COMAule)"18, de la Corte Suprema de fecha 24 de julio de 2003, en donde el actor fue despedido por falta de probidad por haber supuestamente adulterado y falsificado órdenes de compra de combustible, obteniendo con ello ganancias ilícitas. Ambas han sido ampliamente comentadas por la doctrina laboral ${ }^{19}$.

En el año 2011, la Corte Suprema en el caso "Suazo con Codelco Chile"20, reiteró la tesis de la procedencia de una indemnización por daño moral extracontractual producido por un despido abusivo. La Corte precisó que las indemnizaciones tarifadas legales del derecho del trabajo no excluyen, en casos especiales y si se prueban perjuicios extraordinarios, como sería el

\footnotetext{
${ }^{16}$ No obstante, se ha sostenido por civilistas nacionales que la indemnización por despido injustificado tiene una finalidad reparatoria y su forma de cálculo implicaría una suerte de límite impuesto por ley. En este contexto, si el trabajador acredita daños por un monto mayor, debería imputar a dicho valor lo que haya recibido previamente a título de indemnización laboral. Véase: CorraL, Hernán, Lecciones de responsabilidad civil extracontractual (Santiago, Editorial Jurídica de Chile, 2003) pp. 255 y 256.

${ }^{17}$ Esta sentencia, con Rol interno del tribunal N ${ }^{\circ} 698-97$, fue publicada en la Revista Chilena de Derecho, 25 (abril-junio de 1998) 2, pp. 431 ss.

${ }^{18}$ Rol interno del tribunal No $1.726-02$.

${ }^{19}$ Gamonal, Sergio, cit (n. 1), pp. 141 ss.

${ }^{20}$ Rol interno del tribunal $\mathrm{N}^{\circ} 7.270-09$.
} 
caso del daño moral de un trabajador abusivamente despedido, que pueda acumularse una indemnización adicional por el perjuicio moral ${ }^{21}$.

Se trataba de un chofer de camiones de extracción de la mina que trabajaba desde 1973 y fue despedido en el año 2004, por causal disciplinaria. El empleador sostuvo que el trabajador habría efectuado un llamado ilegal a paralización de un grupo de trabajadores, retrasando el ingreso a las labores en la mina por 15 minutos. La sentencia laboral que condenó a la empresa por despido injustificado, se basó en la falta de prueba del empleador y en que, de haber ocurrido los hechos como decía el demando, igualmente hubiera sido desproporcionado un despido disciplinario de un trabajador de esa antigüedad.

La Corte señala que la responsabilidad cuasidelictual civil puede originarse del ejercicio de un derecho cuando éste se realiza sin el debido fundamento, esto es, en forma abusiva y causa daño a un tercero. Esto último, por cuanto los derechos subjetivos tienen una finalidad y han de ejercerse de acuerdo a esos fines. Si alguno, apartándose de tales objetivos y de los postulados generales, ejerce un derecho negligentemente y en el evento que cause daños a terceros, debe indemnizarlos. Este es el caso del empleador que procede al despido de uno de sus subordinados en un contexto que claramente no admitía proceder de ese modo, sea porque se funda en una causal que la ley no ha previsto, porque resulta una medida inapropiada o desproporcionada o, porque precisaba autorización previa ${ }^{22}$.

Respecto de las indemnizaciones tarifadas laborales la Corte Suprema indica que no ha de ignorarse que, según sean las circunstancias del caso, el despido tendrá mayor o menor repercusión en el ámbito personal del exonerado y, habida cuenta, además, que las indemnizaciones reguladas en el ordenamiento especial del trabajo se caracterizan por ser tarifadas, esto es, que equivalen a un estándar mínimo de reparación, no quitan que sobre las mismas pueda determinarse la existencia de un perjuicio que, por su mayor dimensión relativa, amerite ser demostrado y resarcido en ese margen no satisfecho. Dicho de otra manera, en caso alguno las indemnizaciones contempladas en la normativa laboral extinguen o descartan las que pudieran solicitarse por la vía del derecho común. De suerte que es perfectamente viable acumularlas con otras que digan relación con los daños correlativos que acredite quien las demanda, toda vez que las indemnizaciones tarifadas laborales no tienen por finalidad reparar el daño real causado al trabajador separado de sus labores, sino que su naturaleza se encamina hacia finalidades

\footnotetext{
${ }^{21}$ Considerando $2^{\circ}$ de la sentencia de reemplazo.

${ }^{22}$ Considerando $5^{\circ}$ de la sentencia de reemplazo.
} 
de asistencia social, de premio o reconocimiento a la fidelidad del subordinado, y a promover la estabilidad en el empleo ${ }^{23}$.

Para la Corte esta conducta del empleador excede el marco estrictamente contractual y se perfila como una conducta ilícita en el campo extracontractual, dado que no se circunscribe meramente al ámbito del término ordinario del contrato de trabajo ${ }^{24}$. La indemnización de daño moral decretada fue de $\$ 15.000 .000$ de pesos.

\section{NUEVA HIPÓTESIS DE INDEMNIZACIÓN DEL DAÑO MORAL POR TÉRMINO DEL CONTRATO DE TRABAJO}

En la Nueva ley de procedimiento laboral $\mathrm{N}^{\circ} 20.087$, publicada el 3 de enero de 2006, se consagra una figura especial de despido abusivo (artículo 489 CT.) cuando es atentatorio de derechos fundamentales.

Se trata del caso en que la vulneración de los derechos fundamentales se hubiere producido con ocasión del despido. En consecuencia, si se produce un despido y en ese acto se transgrede un derecho fundamental podrá accionarse por esta vía. Se consagran dos figuras: el despido atentatorio de derechos fundamentales y el despido discriminatorio grave. El legislador en el artículo 485 precisó que se trata de los siguientes derechos fundamentales: a la vida, integridad física y psíquica, siempre que la vulneración sea consecuencia directa de actos ocurridos en la relación laboral; vida privada; honra; inviolabilidad de toda forma de comunicación privada; libertad de conciencia y de culto; libertad de opinión; libertad de trabajo; derecho a la no discriminación laboral, y libertad sindical ${ }^{25}$.

En todos estos casos se configura una hipótesis especial de despido abusivo, el despido atentatorio de derechos fundamentales. Se trata de despidos que vulneran cualquiera de las garantías ya citadas, como por ejemplo, cuando se despide a un trabajador por sus creencias religiosas, por las opiniones que ha manifestado en la prensa, por una falsa imputación que afecte su honra, por su orientación sexual, etc.

Los efectos de este despido atentatorio de derechos fundamentales implicarán que el juez decretará el pago de una indemnización equivalente a un

${ }^{23}$ Considerando $6^{\circ}$ de la sentencia de reemplazo. La doctrina laboral concuerda con este razonamiento de la Corte, en el sentido de que la indemnización por años de servicio tiene una naturaleza compleja, de premio a la fidelidad, de fomento de estabilidad en el empleo y de asistencia social. Véase: Gamonal, Sergio, cit. (n. 6) pp. 47 ss.

${ }^{24}$ Considerando $11^{\circ}$ de la sentencia de reemplazo.

${ }^{25}$ Los nuevos artículos 292, 294 y 389 CT. incluyen las vulneraciones a la libertad sindical (prácticas desleales y antisindicales) en este nuevo procedimiento de tutela, como ocurre, por ejemplo, en el despido antisindical (artículo 294). 
mes de remuneración por falta de preaviso; más el pago de la indemnización del artículo 163 CT., de años de servicio, si procediere; más el pago de los recargos del artículo $168 \mathrm{CT}$.y, finalmente, deberá fijar una in de m nización adicional no inferior a seis meses ni superior a once meses de la última remuneración mensual.

Por lo tanto, aceptado el despido atentatorio de derechos fundamentales el legislador lo considera injustificado según las reglas generales del artículo 168 CT., y además se sanciona al empleador con una indemnización adicional o extra con piso de seis y tope de once remuneraciones, y que es fijada incidentalmente por el juez laboral.

Esta indemnización es por el daño material y moral causado al afectado, en especial por este último al tratarse de derechos fundamentales con una importante incidencia en los intereses extrapatrimoniales del trabajador.

Parte de la doctrina estima que la indemnización adicional es una indemnización sancionatoria y que, por ende, quedaría pendiente la indemnización del daño moral producido ${ }^{26}$. Otros autores estiman que esta indemnización no es una simple tarificación por antigüedad, sino que deja un margen de apreciación importante al juez de la causa acerca del daño producido, especialmente el moral. De esta forma, el legislador fija un piso y un tope para evaluar los daños, recogiendo con ello la experiencia de otros países, en los que se ha evaluado el daño moral laboral decretando el pago de un número determinado de remuneraciones ${ }^{27}$.

En la misma línea, en la doctrina civil, Barros señala que la indemnización del daño moral está sujeta a condiciones de responsabilidad diferente que la patrimonial, pudiendo el legislador estatuir criterios razonables o baremos para limitar la indemnización ${ }^{28}$.

La otra figura que se consagra en este nuevo procedimiento es el des pido discriminatorio grave. En estos casos, el despido es declarado discriminatorio por haber infringido el inciso cuarto del artículo $2 \mathrm{CT}$. y, además, es calificado como grave por resolución fundada. Si no es grave pero sí discriminatorio el despido es solamente atentatorio de derechos fundamentales, y se rige por los efectos ya explicados.

Son despidos discriminatorios los que efectúan, al tenor de los dispuesto en el artículo 2 CT., distinciones, exclusiones o preferencias basadas en motivos de raza, color, sexo, edad, estado civil, sindicación, religión, opinión política, nacionalidad, ascendencia nacional u origen social, que tengan por

${ }^{26}$ UGARTE, José Luis, cit. (n. 4), p. 90.

${ }^{27}$ Gamonal, Sergio, cit. (n. 4), p. 39.

${ }^{28}$ BARros, Enrique, Tratado de responsabilidad extracontractual (Santiago, Editorial Jurídica de Chile, 2007), p. 253 y n. 112. 
objeto anular o alterar la igualdad de oportunidades o de trato en el empleo y la ocupación.

Además, el despido discriminatorio deberá ser grave, o sea el juez deberá sopesar los elementos fácticos de la discriminación, valorando el peso y entidad del daño provocado.

El despido discriminatorio grave es un despido nulo y por ello el trabajador tiene la siguiente opción: de reincorporarse a la empresa, o de exigir los pagos ya reseñados respecto del despido atentatorio de derechos fundamentales.

En estos dos tipos de despido abusivo (atentatorio de derechos fundamentales y discriminatorio grave) se comprende la indemnización del daño moral laboral contractual por medio de la indemnización adicional o extra con piso de seis y tope de once remuneraciones.

Comentaremos brevemente tres sentencias en que, más allá de lo expresado en sus fundamentos, se concede por medio de esta indemnización la reparación de perjuicios morales de los trabajadores.

En el caso "Jara Miranda con Redbus Urbano" 29 , una trabajadora contratada recientemente es acosada sexualmente por su jefe directo. La trabajadora acosada presenta una denuncia al jefe superior en la empresa, quien le solicitó que no la formalizara por escrito, comprometiéndose a tratar el tema en la próxima reunión de jefatura. Pocos días después la afectada fue cambiada de lugar de trabajo y su nuevo jefe le exigió retirar la denuncia bajo amenaza de ser despedida, a lo cual ella respondió que no la retiraría y que no era la primera víctima del acosador, ya que sabía que lo había sido otra inspectora y no quería que hubiera nuevas víctimas. Dos días después, el directorio del sindicato de la empresa, en pleno conocimiento de la situación, presentó una carta al Presidente ejecutivo y representante legal de la empresa, protestando por la negativa de la empleadora de dar curso a la investigación por acoso sexual. Finalmente, al día siguiente la trabajadora recibe carta de aviso de término de su contrato de trabajo por vencimiento del plazo.

El tribunal estimó que había indicios suficientes considerando que la práctica en la empresa era contratar a plazo a los trabajadores para probarlos y luego contratarlos en forma indefinida. Como la trabajadora había tenido buen desempeño no era lógico su despido, a lo que se suma que la denuncia presentada por ella había incomodado a la empresa, y ésta última ni siquiera había investigado los hechos de acoso. Dada la breve antigüedad de la demandante (que no le permitía acceder a una indemnización por años de servicio) el juez decretó una indemnización adicional de 6 meses de remuneración.

${ }^{29} 2^{\circ}$ Juzgado de Letras del Trabajo de Santiago, Rol interno del tribunal N ${ }^{\circ} \mathrm{T}-4-$ 2009. El recurso de nulidad fue rechazado. 


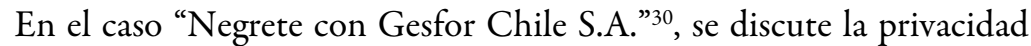
del correo electrónico institucional (casilla de la empresa) de un ex trabajador, el que era redireccionado a la gerencia de la empresa. De esta forma la jefatura se entera de los emails enviados entre este ex trabajador (que crea su propia empresa) y otros trabajadores de la compañía, por medio de los cuales se les solicitaba a estos últimos algunos servicios de soporte para su nuevo negocio. Con esa información, se decidió el despido de estos últimos presumiendo el haber realizado negociaciones incompatibles del mismo giro de la empresa.

La sentencia precisa que es evidente la privacidad del email redireccionado, expresando que si, por ejemplo, un trabajador escribe una carta a un familiar en una hoja de papel de propiedad de la empresa y con un lápiz que ha sido proporcionado por su empleador y la dispone en un sobre cerrado (también de la empresa) indicando con precisión su destinatario; a nadie se le ocurriría pensar que porque la empresa es dueña de la hoja y el sobre utilizados, pueda su empleador -legítimamente-, por ese sólo hecho, abrirla e imponerse de su contenido, justamente porque existe un ámbito indicativo de lo privado que se basa en su contenido de la comunicación, y no en el continente. En este caso, la empresa sabía que dicha comunicación no iba destinada a ella, sin embargo, ello no importó porque creyó tener motivos suficientes para imponerse del contenido y servirse de él en contra del destinatario. Uno de esos motivos es que era dueña del medio y eso se debe descartar, puesto que la propiedad del medio no es determinante para calificar la privacidad de una comunicación. Del mismo modo que ser dueño del servicio de telefonía o del teléfono no habilita para escuchar las conversaciones telefónicas ${ }^{31}$.

En definitiva, la empresa es condenada por despido atentatorio a la inviolabilidad de comunicación privada del trabajador y a pagar 9 meses de indemnización adicional.

Finalmente, en el caso "Omerovich con ISS Servicios Generales" ${ }^{2}$, una trabajadora contratada para labores de aseo es despedida el primer día de sus servicios al descubrirse que cojea. Como no había señalado esta discapacidad en la entrevista de trabajo se la trató de mentirosa y sinvergüenza y de coja discapacitada. Además, el empleador rompió frente de ella el contrato que se había escriturado.

La trabajadora señaló que perfectamente podía realizar las labores y que los bastones o muletas los ocupaba sólo para transitar en la vía pública. Para

${ }^{30} 2^{\circ}$ Juzgado de Letras del Trabajo de Santiago, Rol interno del tribunal $N^{\circ} \mathrm{T}-385-$ 2011. El recurso de nulidad está pendiente en la Corte de Apelaciones de Santiago.

${ }^{31}$ Considerando $7^{\circ}$.

${ }^{32} 1^{\text {er }}$ Juzgado de Letras del Trabajo de Santiago, Rol interno del tribunal $N^{\circ}$ T-3852011. El recurso de nulidad fue rechazado. 
efectos de acreditar el daño moral la demandante incorporó certificado médico y certificado de atención psicológica que dan cuenta que la actora presenta un trastorno adaptativo ansioso severo, prescribiéndole medicamentos al respecto. Se concluye que hubo perjuicio a la integridad y a la salud mental de la demandante tras haber sido discriminada. Lo anterior fue coincidente con la evaluación psicológica efectuada, donde se constató que esta trabajadora estaba viviendo un episodio de estrés postraumático en relación al incidente vivido, estimando un período de recuperación sometida a tratamiento sicológico y psiquiátrico de 6 meses.

La sentencia concluye que este despido violó la igualdad de oportunidades en el empleo de la demandante, decretando una indemnización adicional de 6 remuneraciones y una indemnización extra de otros 6 meses de remuneración por concepto de daño moral.

\section{Conclusiones}

El daño moral en materia laboral constituye un importante complemento excepcional a las indemnizaciones tarifadas contempladas por el legislador.

Aunque es cierto que la tarifa es ventajosa, ya que exime de prueba al trabajador y permite al empleador conocer de antemano los costos del despido, hay casos excepcionales en los cuales debe ser complementada con una indemnización extra, de daño moral, según hemos postulados en el cuerpo de este trabajo.

Es en este sentido que deben entenderse las sentencias nacionales que hemos comentado y las enmiendas legales recientes que consagran el despido atentatorio de derechos fundamentales, adjuntando una indemnización especial entre 6 y 11 meses de remuneración. Consideramos que esta indemnización es por daño moral, y su base y tope fijan estándares al juez del trabajo con miras a hacer justicia sin por ello desequilibrar en demasía los costos del empleador, sobre todo de la pequeña y micro empresa.

La naturaleza de esta indemnización no está del todo determinada en el derecho chileno, dado que, como señalamos anteriormente, para algunos autores esta indemnización adicional es sancionatoria y sería procedente decretar otra indemnización extra en caso de probarse daño morales por el despido atentatorio de derechos fundamentales. Esta es la tesis sostenida en la última sentencia que hemos comentado.

Estimamos que esta evolución del derecho del trabajo chileno es muy importante y fortalece la tutela del trabajador. Por medio de estas reformas legales, el daño moral por término de contrato ha pasado de ser una hipótesis doctrinaria recogida en algunas sentencias, denominadas en este 
artículo hipótesis tradicionales, a constituir un derecho cierto y regulado en el Código del Trabajo.

\section{BiBLIOGRAFÍA}

BARros, Enrique, Tratado de responsabilidad extracontractual (Santiago, Editorial Jurídica de Chile, 2007).

CaAmaño, Eduardo, El Derecho a la no discriminación en el empleo (Santiago, LexisNexis, 2005).

Corral, Hernán, Lecciones de responsabilidad civil extracontractual (Santiago, Editorial Jurídica de Chile, 2003).

DiEz SCHWERTER, José Luis, El daño extracontractual. Jurisprudencia y doctrina (Santiago, Editorial Jurídica de Chile, 1997).

Domínguez Águila, Ramón - Domínguez Benavente, Ramón, Daño moral en la responsabilidad contractual. Ausencia de norma excluyente de su reparación, Comentario de Jurisprudencia, Revista de Derecho, 196 (Universidad de Concepción, julio/diciembre de 1994).

Domínguez Águila, Ramón - Domínguez Benavente, Ramón, Responsabilidad contractual. Daño moral. Cúmulo de responsabilidades. Prueba del daño moral. Comentario de Jurisprudencia, en Revista de Derecho, 193 (Universidad de Concepción, enero/junio de 1993),

Domínguez Águila, Ramón, Reparación del daño moral por despido injustificado, en Revista Chilena de Derecho, 25 (1998) 2.

Domínguez Hidalgo, Carmen, La indemnización por daño moral. Modernas tendencias en el derecho civil chileno y comparado, en Revista Chilena de Derecho, 25 (1998) 1.

ERmida, Oscar, El concepto de despido abusivo, en Derecho Laboral, 27 (Montevideo, julio-septiembre de 1984) 135.

Fueyo Laneri, Fernando, Instituciones de Derecho civil moderno (Santiago, Editorial Jurídica de Chile, 1990).

Gamonal, Sergio, Ciudadanía en la empresa o los derechos fundamentales inespecificos (Montevideo, Fundación de Cultura Universitaria, 2004).

GAMONAL, Sergio, El daño moral en el contrato de trabajo (2a edición, Santiago, LexisNexis, 2007).

GAMONAL, Sergio, El daño moral por término de contrato de trabajo (Santiago, Editrem, 2000).

Gamonal, Sergio, El procedimiento de tutela de derechos laborales (2a edición, Santiago, LexisNexis, 2008).

Gamonal, Sergio, Trabajo y Derecho (Santiago, AbeledoPerrot, 2010).

GuZmán Brito, Alejandro, El Derecho privado constitucional de Chile (Valparaíso, Ediciones Universitarias de Valparaíso Universidad Católica de Valparaíso, 2001).

Illanes Ríos, Claudio, El daño moral en la responsabilidad contractual, charla dictada el 8 de septiembre de 1994 en el Colegio de Abogados, publicada en diciembre de 1994 por el Colegio de Abogados.

Mangarelli, Cristina - Rosenbaum Rimolo, Jorge, El despido abusivo en el derecho uruguayo, en Derecho Laboral, 31 (Montevideo, julio-septiembre de 1988) 151. 
MARTORell, Ernesto, Indemnización del daño moral por despido (2a edición, Buenos Aires, Hammurabi, 1994).

Melis, Christian, Los derechos fundamentales de los trabajadores como limites a los poderes empresariales (Santiago, LegalPublishing, 2009).

Pizarro, Ramón Daniel, Daño moral (Buenos Aires, Hammurabi, 1996).

Süsseskind, Arnaldo - Maranhäo, Délio - Vianna, Segadas - Texeira, Lima, Instituçiôes de Direito do trabalho, (Sao Paulo, LTr, 1997).

TOMASEllo Hart, Leslie, El daño moral en la responsabilidad contractual (Santiago, Editorial Jurídica de Chile, 1969).

Ugarte, José Luis, El nuevo Derecho del trabajo (Santiago, Editorial Universitaria, 2004).

UgARTE, José Luis, Tutela de derechos fundamentales del trabajador (Santiago, LegalPublishing, 2009).

VÁzquez Vialard, Antonio, La responsabilidad en el derecho del trabajo (Buenos Aires, Astrea, 1988). 